\title{
Orthopedic surgery: Beware of 10 intra operative nightmare situations other than common medico-surgical complications
}

\author{
Mohit J Jain ${ }^{1}$, Kinjal J Mavani ${ }^{2}$ \\ ${ }^{1}$ Dr Mohit J Jain, M.S.(Ortho.), Department of Orthopaedics, Sanjeevani Multispeciality Hospital, Jetpur, Gujarat, India. ${ }^{2}$ Dr \\ Kinjal J Mavani, M.D.S. (Ortho.), Department of Orthodontics, Maratha Mandal Dental College, Belgaum, India
}

Address for Correspondence: Dr Mohit J Jain [M.S.(Ortho.)], Department of Orthopaedics, Sanjeevani Multispeciality Hospital, Jetpur, Gujarat, India. E-mail: dr.mits4u@gmail.com

\begin{abstract}
Orthopedics is considered an art of jugglery and carpentry. There are so many technical and situational difficulties other than medico-surgical complication and still challengingly unique of surgeries pertaining to orthopedics. We have reviewed orthopedic literature to conclude 10 nightmare situations which are though less common but discussed even lesser. They include IITV (Image Intensifier), Suction, Cauterization, Lighting, Drilling, Implants, Cooling and ventilation, Patient positioning, Wrong side/site and Accidental prick or injuries related issues. Considering all this problems as a single issue, its prevalence is sometime comparable with the known complication like infection and other morbidity and mortality. The liability of non-biological issues on doctor or hospital and narrow margin between technical error and negligence has made reporting of such situation even in front of medical fraternity a rarity. Appropriate pre-operative planning and keeping the backups available can dramatically reduce the encounter with these preventable situations. These situations are definitely like a 'nightmare' for any orthopedic surgeon, now it is up to us when we are going to take the 'wake-up call
\end{abstract}

Keywords: Nightmare situation; Orthopedic surgery; Prevention; Technical problem

\section{Introduction}

As orthopedic surgeons, we utilize more technology, more implantable devices, more industry support, and more mechanical innovations than any other branch of medicine according to Capozzi JD et al [1]. This has made us more vulnerable to many technical nightmare situations, of which most other medical fields are unaware.

Almost each of these situations is faced by most of the orthopedic surgeons at least once in a lifetime, sooner or later. Just because these are not medico surgical complications, we have been ignoring them till now.

Manuscript Received: $06^{\text {th }}$ September 2016

Reviewed: $12^{\text {th }}$ September 2016

Author Corrected: $19^{\text {th }}$ September 2016

Accepted for Publication: 30 $0^{\text {th }}$ September 2016
Perhaps from doctors to hospital management and from staff to instrument companies, nobody wants to take the responsibility. It's high time to accept the technical pitfalls of our fraternity and do some genuine research on it.

\section{The Top '10'}

(1) IITV (X ray image intensifier): It has got no. 1 rank because of the dependency of modern orthopedics on IITV. Nowadays very few bony surgeries exist which really don't need it. The image intensifier is used in for intraoperative assessment of fracture reduction and implant placement, especially with the increasing trend toward use of closed nailing devices according to Lo NN et al. 
The use of fluoroscopy has increased tremendously in field of orthopedics [2]. The image intensifiers have enabled orthopedic surgeons to become technically more proficient and decrease the morbidity of the patient by minimizing area of operative field and decreasing operative time [3].

Old machines, voltage and wiring related problems, nonmaintenance are the reasons behind failure. Improper handling by non-qualified person and multiple frequent shoot outs demanded by operating surgeon may lead to hanging problems. AMC (Annual Maintenance Contract) and $\mathrm{CMC}$ (Comprehensive Maintenance contract) with the manufacturer are important in preventing problems.

The risk of an orthopedic surgeon contracting cancer is significantly higher than that of a non-orthopedic professional and eight times more than that of an unexposed worker [4].

Qualified technician only should operate the machine rather than learning or trainee doctors and it also help in radiation reduction [5]. Unfortunately once it stops working during surgery, there is less we can do except converting a closed surgery into an open one if possible.

(2) Suction: Operation field suctioning catheter allows the suctioning of blood, flushing solutions, and discharges from the operation field. Invent of suction catheter was once considered as new era of surgical drainage by suction applicable to every surgical field [6].

Proper suctioning of oozing blood is mandatory for any open surgery nowadays. Kelly EA et al emphasized that adequate surgical field visualization is imperative for successful outcomes in their study [7].

Clear and visible surgical field not only improve quality of surgery but also reduce surgical time and stress. General anesthesia also requires continuous suction from tube.

Suction tube connections and blockage of cannula are the issues rather than machine proper. Good back up along with the central suction line is the solution.
(3) Cauterization: Electro-cautery, also known as thermal cautery, refers to a process in which a direct or alternating current is passed through a resistant metal wire electrode, generating heat. The heated electrode is then applied to living tissue to achieve hemostasis or varying degrees of tissue destruction [8].

Bloodless field is the basic requirement of a meticulous surgery. Yang $\mathrm{Y}$ et al observed that electro cautery is now more commonly adopted to not only achieve intraoperative hemostasis but cutting and dissecting out many structures during surgical exposure [9].

Spine and micro surgery is almost impossible without cauterization especially bipolar. Excessive blood loss is also a life-threatening complication prevented by cautery. Back up machine along with the use of prophylactic tourniquet (without inflating) is recommended.

(4) Lighting: Surgical light is also called operating light or a surgical lighthead. It is used to illuminate patient's cavity or local area during the operation.

Most of the operating room lights available on the American market are thoughtfully designed and, if properly employed, will produce a lighted operative field in accordance with the specifications developed by the Hospital Committee of the Illuminating Engineering Society [10].

Visibility is the utmost important pre requisite for a hassle-free procedure. Inadequate illumination, improper focusing and shadowing are the main problems encountered.

Takeshi Ide et al reveled that LED lights are superior due to less heat radiation, pure white illumination, improved shadow control and more accurate color rendition in comparison to halogen with even lesser power consumption [11]. High quality stabilizers should be used along with to deal with voltage related fluctuations.

(5) Drilling machine: Orthopedic surgeries frequently require electric or pneumatic drills for bone drilling. Hand drill is becoming outdated now a day. Pneumatic drills 
have issues of air hoses. Electronic drilling machines are also becoming wireless, i.e. battery operated as observed by Railton R et al but costly [12].

Specialized surgeries like joint replacement require bone cutting and not only holes making. So failure of drilling machine is not something which can be managed manually now. But still, keeping a backup drill machine along with hand drill is a safer option.

Moreover, to achieve a competent level of performance for bicortical bone, trainees should learn how to optimize their drilling through the bone rather than just plunge (technical error) prevention [13].

(6) Implants and instrumentation: Unavailability of proper implant on table during surgery is not as uncommon as it is thought of. Missing out in autoclaving with other instruments, unviability of proper sided (left or right) or sized implant, inadequate or loss of sterility, breakage and opting for plan B during surgery requiring different implant are some issues.

Pre-operative implant should be checked by operating surgeon with labeling and backup instruments before autoclaving. Accidental fall of implant during surgery is also not as uncommon as thought of. Khan $\mathrm{S}$ at al in their study of 120 random orthopedic surgeries, rate of accidental fall of implant or instruments was found as high as 30 percent [14].

It happens more commonly during emergency surgery than elective surgery and mostly by operating surgeon followed by assistant and staff nurse. In their study from 1990 to 2005 using the Nationwide Inpatient Sample (NIS), Ong KL et al found out that hospitalisations due to accidental falls on level surfaces or from stairs increased by $306 \%$ or $310 \%$ respectively with overall increase in incidence upto $35 \%$.

Falls involving orthopedic revision surgery (re-operation) were relatively rare, but cost 50\% (median) more than those that did not involve re-operation in 2005 [15].
(7) Cooling and ventilation: Orthopedic surgeries require highest amount of physical strength than any other medical specialties. Use of lead aprons with surgical gown further makes surgeon sweat a lot. Proper cooling is also necessary to reduce infection chances and sometime for cementing process also.

Laminar (vertical) air system in operating room provides ideal ventilation along with cooling but failure of such systems is not uncommon and current evidences by James $\mathrm{M}$ et al suggest that it has no significant advantage in controlling infection rate [16][17].

\section{(8) Patient positioning, traction, reduction, retraction:}

Orthopedic surgeries are quite versatile in terms of patient positioning. Loss of traction, reduction and continuous retraction are some unique difficulties an orthopedic surgeon deals with. Bonnaig $\mathrm{N}$ et al in their study found out that it is not only associated with substantial morbidity but also a major area of litigation, particularly in case of nerve injury (Ulnar, Common peroneal, Brachial plexus) and pressure sores and well leg compartment syndrome [18].

Operating surgeon should confirm the adequate position, traction and reduction by himself before getting scrubbed. Properly equipped operating table, self-retaining retractors and trained assistants aid a lot.

(9) Wrong side, wrong site, wrong procedure or wrong patient: Rightly termed as "never events"-errors that should never occur and indicate serious underlying safety problems. Improper or wrong labeling, marking or documentation along with series of environmental and human errors makes this preventable complication possible. A seminal study of Kwaan MR et al estimated that such errors occur in approximately 1 of 112,000 surgical procedures [19].

Role of universal protocols and multiple check lists to avoid this never in a lifetime situation has been very well proven by Panesar SS et al [20]. Exploration of wrong sided limb or wrong level of spine is not very rare in orthopedics. 
Although wrong-site surgery is rare, Meinberg EG et al found that $21 \%$ of hand surgeons reported performing it at least once during their careers and after "Sign Your Site" campaign of AAOS, $45 \%$ of orthopedic hand surgeons have changed their practice habits, and almost all routinely take some action to prevent wrong-site surgery [21].

In an unfortunate incident of Wrong Side Surgery, that author himself has come a crossed involved a pediatric patient, minimally displaced forearm fracture, general anesthesia prior to surgeon's arrival in operating room, wrong sided painting-draping by assistant, pre-operative $\mathrm{X}$-ray on the view box without side marker and false sense of perfect reduction during nailing by under training orthopedic surgeon without any supervision. So many things to be learn from just one case.

(10) Accidental prick or injuries: Despite legislation and advances in sharps safety technology, Jagger $\mathrm{J}$ et al found out that surgical injuries continued to increase during the period that nonsurgical injuries decreased significantly [22].

Sharpe instrumentations like guide pins and $\mathrm{k}$ wires, drilling and rotating parts like drill bits and saws, forceful maneuvers like traction and hammering and suturing when the orthopedic surgeon is most tired and impatient, all of them makes it a risky business for an orthopedic surgeon.

Use of multiple and more protective gloves like Encore ${ }^{\circledR}$ Orthopedic, surgical staplers and careful handling of machinery warrants safety to the surgeon and assisting staff. Updated U.S. Public Health Service advised universal precautions of safety have to be followed even in emergency procedures where HIV and HBsAg status is unknown and post exposure prophylaxis kit should be kept handy [23].

\section{Conclusion}

Considering all this problems as a single issue, its prevalence is sometime comparable with the known complication like infection and other morbidity and mortality. Because of many other challenging situations which we haven't reviewed and lack of proper reporting fashion, these intra operative technical problems other than medico-surgical complications might be just a tip of an iceberg in actual sense.

An honest reporting system without the fear of vicarious liability and dedicated research in this field is the need of time.

We firmly believe that pre-operative planning with the backups is the solution of these preventable situations. Campaigns like Universal Precautions or Mark Your Site have definitely had their impact but still many more to be done.

Sharing the unforgivable complications by the fraternity and becoming advanced not only in terms of surgical skills but also in sharing the responsibilities is the need of time before it's too late. Very few surgeons' 'nightmare' can become a 'wake up call' for many.

Conflict of interest: None declared.

Funding: Nil, Permission from IRB: Yes

\section{References}

1. Capozzi JD, Rhodes R. Ethical challenges in orthopedic surgery. Curr Rev Musculoskelet Med.June2015;v.8(2): 139-144,doi:10.1007/s12178-015-9274-y.

2. Lo NN, Goh PS, Khong KS. Radiation dosage from use of the image intensifier in orthopaedic surgery. Singapore medical journal. March 1996; 37(1):69-71.

3. Badman BL, Rill L, Butkovich M, Arreola M, Griend RAV. Radiation Exposure with Use of the Mini-C-Arm For Routine Orthopaedic Imaging Procedures. J Bone Joint Surg Am. 2005; $87 \quad$ (1):13-17. doi: 10.2106/JBJS.D.02162.

4. Giannoudis PV, McGuigan J, Shaw DL. Ionising radiation during internal fixation of extracapsular neck of femur fractures. Injury. 1998; 29:469-72. doi: $10.1308 / 003588406$ X98702. 
5. MJ Oddy, $\mathrm{CH}$ Aldam. Ionising radiation exposure to orthopaedic trainees: the effect of sub-specialty training. Ann R Coll Surg Engl. 2006;88(3):297-301.doi: $10.1308 / 003588406 \times 98702$.

6. Chaffin RC. New era of surgical drainage by suction applicable to every surgical field. Clin Med (Northfield). 1946 Dec;53(12):341-4.

7. Kelly EA, Gollapudy S, Riess M, Woehlck HJ, Poetker DM. Quality of surgical field during endoscopic sinus surgery: A systematic literature review of the effect of total intravenous compared to inhalational anesthesia. Int Forum Allergy Rhinol. 2013 Jun; 3(6): 474-481.

8. Pollock SV, Bolognia JL, Jorrizo JL, Rupini RP. Dermatology. 2008; $2^{\text {nd }}$ Edition, Ch 140- Electrosurgery.

9. Yang Y, Zhang LC, Fei Xu, Jia Li and Yong-ming. Bipolar sealer not superior to standard electrocautery in primary total hip arthroplasty: a meta-analysis. J Orthop Surg Res. 2014; 9: 92. DOI: 10.1186/s13018-014-0092-5.

10. Beck WB. Lighting the operating room-criteria and choice. AORN Journal. October 1971; Volume 14, Issue 4, Pages 46-49.

11. Ide T, Kinugawa Y, Nobae Y, Suzuki T, Tanaka Y, Toda I, Tsubota K. LED Light Characteristics for Surgical Shadowless Lamps and Surgical Loupes. Plast Reconstr Surg Glob Open. 2015 Nov;3 (11):e562. doi:10.1097/GOX.0000000000000498.

12. Railton R, Pringle RM, Shaw A. Evaluation of Makita electric drills for orthopaedic surgery. J Med Eng Technol.1988 Jan-Feb;12(1):20-3.

13. Khokhotva M, Backstein D, Dubrowski. Outcome errors are not necessary for learning orthopedic bone drilling. Canadian journal of surgery; May 2009, 52(2):98-102.

14. Khan S, Kumar A, Varshney MK, Trikha V, Yadav C. Accidentally falling instruments during orthopaedic surgery: time to wake up! ANZ J Surg. 2008 Sep;78(9):794-5. doi: 10.1111/j.1445-2197.2008.04652.x.

15. Ong KL, Lau E, Moore T, Heller MF. Accidental falls involving medical implant re-operation. Injury. 2009 Oct;40(10):1088-92. doi: 10.1016/j.injury.2009.05.007.

16. James M, Khan WS, Nannaparaju MR, Bhamra JS, Jones RM. Current Evidence for the Use of Laminar Flow in Reducing Infection Rates in Total Joint Arthroplasty. Open Orthop J. 2015; 9: 495-498. doi: $10.2174 / 1874325001509010495$.

17. Christian, Uwe H, Dorit S, Franz, Petra G, Henning R. Operating Room Ventilation With Laminar Airflow Shows No Protective Effect on the Surgical Site Infection Rate in Orthopedic and Abdominal Surgery. Annals of Surgery; Nov 2008-Volume 248-Issue 5-pp 695-700. doi: 10.1097/SLA.0b013e31818b757d.

18. Bonnaig N, Dailey S, Archdeacon M. Current Concepts Review: Proper Patient Positioning and Complication Prevention in Orthopaedic Surgery. The Journal of Bone and Joint Surgery. · July 2014; 96(13):1135-1140. DOI: 10.2106/JBJS.M.01267

19. Kwaan MR, Studdert DM, Zinner MJ, Gawande AA. Incidence, patterns, and prevention of wrong-site surgery. Arch Surg. 2006 Apr;141(4):353-7; discussion 357-8.

20. Panesar SS, Noble DJ, Mirza SB, Patel B, Mann B, Emerton M, Cleary K, Sheikh A, Bhandari M. Can the surgical checklist reduce the risk of wrong site surgery in orthopaedics? - can the checklist help? Supporting evidence from analysis of a national patient incident reporting system. J Orthop Surg Res. 2011; 6: 18.

21. Meinberg EG1, Stern PJ. Incidence of wrong-site surgery among hand surgeons. J Bone Joint Surg Am. 2003 Feb;85-A(2):193-7.

22. Jagger J, Berguer R, Phillips EK, Parker G, Gomaa AE. Increase in Sharps Injuries in Surgical Settings Versus Nonsurgical Settings after Passage of National 
Needlestick Legislation. April 2010; Volume 210, Issue 4, Pages 496-502. doi: 10.1016/j.jamcollsurg.2009.12.018.

23. Updated U.S. Public Health Service guidelines for the management of occupational exposures to $\mathrm{HBV}, \mathrm{HCV}$, and HIV and recommendations for post exposure prophylaxis. Morbidity and Mortality Weekly Report. 2001;50(11):1-52.

\section{How to cite this article?}

Mohit J Jain , Kinjal J Mavani Orthopedic surgery: Beware of 10 intra operative nightmare situations other than common medico-surgical complications. Int J surg Orthopedics 2016;2(3):49-54.doi: 10.17511/ijoso.2016.i03.05 